\title{
Chu to give keynote address at Technology Innovation Forum X
}

Q teven Chu will present the keynote Oaddress at the Tenth Technology Innovation Forum: "U.S. National Laboratories as Engines for Innovation." Government research laboratories are a great national resource for technology innovation and development. The forum explores the opportunities and challenges in how best to uti-

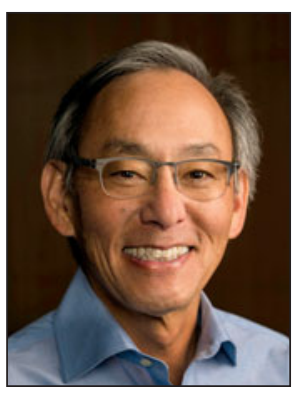

lize government labs for bringing new materials technologies to market. Through a series of talks and panel discussions, it will examine case studies from around the world and highlight best practices that are viable.

Chu is the William R. Kenan, Jr., Professor of Physics and Professor of Molecular and Cellular Physiology in the medical school at Stanford University. He has published 260 papers in atomic and polymer physics, biophysics, biology, biomedicine and batteries, and holds 10 patents. Chu was the 12 th US Secretary of Energy from January 2009 until the end of April 2013. As the first scientist to hold a Cabinet position and the longest serving energy secretary, he recruited outstanding scientists and engineers into the Department of Energy. He began several initiatives, including ARPA-E (Advanced Research Projects Agency-Energy), the Energy Innovation Hubs, and the US-China Clean Energy Research Center (CERC). Chu has numerous awards, including the 1997 Nobel Prize in Physics shared with Claude Cohen-Tannoudji and William D. Phillips, and he holds 26 honorary degrees.

For more information about the Technology Innovation Forum X, visit www.mrs.org/spring-2016-technologyinnovation-forum.

\section{Technology Innovation}

Forum X

Tuesday, March 29

PCC, Lower Level

Hall 5-The Exhibit Stage

\section{Unlocking Innovation \\ at National Labs \\ How Do Government Research \\ Laboratories Most Effectively \\ Help Bring About Technology \\ Commercialization?}

\section{- Keynote Address \\ Steven Chu \\ 10:15 am - 11:15 am}

- Panel Discussions

11:30 am - 4:30 pm

\section{Forrest keynote to kick off second edition of iMatSci}

$T^{1}$ he second edition of iMatSciInnovation in Materials Scienceprovides materials-based innovators with a platform to demonstrate the practical applications of their technologies, while connecting these innovators to potential sources of venture capital. An international pool of startups will

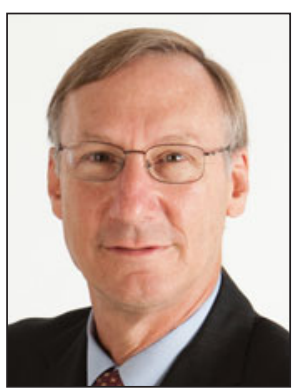

be judged by professional technology innovators and will compete for cash prizes.

A keynote address on Transformational Innovation by Stephen Forrest, University of Michigan, kicks off the event, which also features a panel discussion on early-stage investment and venture funding.

Forrest is a professor of electrical engineering and computer science, physics, and materials science and engineering at the University of Michigan. He holds a BA degree in physics from the University of California-Berkeley, and MSc and $\mathrm{PhD}$ degrees in physics from the University of Michigan. He has authored $\sim 554$ papers in refereed journals and holds 280 patents. In May 2015, Forrest was named the University of Michigan's Distinguished University Innovator. He is co-founder or founding participant of several companies, and serves on the board of governors of the Technion-Israel Institute of Technology.

The Venture Funding Panel Discussion provides a mechanism to examine early-stage investment opportunities, assist entrepreneurs and earlystage growth companies, and be a quality source for information. Get your venture funding questions answered, such as How can I fund my venture with someone else's money? What do angel investors and venture capital investors look at when making a funding decision? What do angels and ventures fund? For more information about iMatSci events, visit www.mrs.org/spring-2016-imatsci.

iMatSci- Innovation in Materials Science

Wednesday, March 30

PCC, Lower Level

Hall 5-Exhibit

- Innovator Demonstrations

11:00 am - 5:30 pm

- Keynote Address

Stephen Forrest

1:15 am - 12:00 pm

- Venture Funding

Panel Discussion

1:30 pm - 2:30 pm

- iMatSci Winners Announced 5:15 pm 